\title{
UM NOVO COMPLEXO HÍBRIDO FORMADO A PARTIR DE PIPLARTINA E O ÍON VANADILA: SÍNTESE, CARACTERIZAÇÃO E ESTUDO DA ATIVIDADE BIOLÓGICA
}

\author{
Giselle B. Bezerra ${ }^{a}$, Janete M. Araújo ${ }^{\mathrm{b}}$, Mônica F. Beliana, Wagner E. da Silva ${ }^{a}$ e Clécio S. Ramos ${ }^{\mathrm{a}, *}$ \\ aDepartamento de Química, Universidade Federal Rural de Pernambuco, 52171-900 Recife - PE, Brasil \\ bepartamento de Antibiótico, Universidade Federal de Pernambuco, 50670-901 Recife - PE, Brasil
}

Recebido em 11/02/2017; aceito em 24/05/2017; publicado na web em 19/07/2017

\begin{abstract}
A NOVEL HYBRID COMPLEX FORMED FROM THE PIPLARTINE AND VANADIL ION: SYNTHESIS, CHARACTERIZATION AND BIOLOGICAL ACTIVITY STUDY. The synthesis, characterization and antimicrobial activity of novel vanadium (IV) complex derived of amide natural piplartine is reported. The minimum inhibitory concentrations (MIC) of complex, piplartine and vanadyl sulphate used in the synthesis were determined against six bacteria and one fungus. The complex exhibited good activity with minimal inhibitory concentration values ranging from 156.2 to $625 \mu \mathrm{gL}^{-1}$, it was observed the lowest value for the Escherichia coli bacteria with MIC $156.2 \mu \mathrm{g} \mathrm{mL}-1$ and Microsporum gypseum fungus with MIC $312.5 \mu \mathrm{g} / \mathrm{mL}$. In overall, the complex showed better antimicrobial activity than the piplartine. Additionally, the V-PIP complex was completely soluble in water, on the contrary of the piplartine free; which means that the proposal complex consists in a potential candidate to drug.
\end{abstract}

Keywords: hybrid complex; vanadyl ion; piplartine; antimicrobial.

\section{INTRODUÇÃO}

Há um crescente interesse em estudos direcionados às alternativas para a síntese de novos complexos bioativos. Uma estratégia interessante e eficaz é fazer uso de ligantes (moléculas orgânicas) oriundos de produtos naturais, semi-sintéticos ou sintéticos, que apresentem atividade biológica comprovada. ${ }^{1-4} \mathrm{O}$ objetivo do uso de ligantes que já possuem atividade biológica é produzir um complexo que apresente efeito aditivo ou sinérgico, fazendo com que o candidato a fármaco apresente todas as potencialidades do ligante aliado ao íon metálico, que também apresente atividade. Os complexos que apresentam ligantes bioativos são denominados híbridos.

Complexos híbridos, por apresentar duas parcelas funcionais bioativas, vêm sendo desenvolvidos na perspectiva de contornar fatores de resistência, principalmente aos fatores de resistência às múltiplas drogas (do inglês, multi-drug resistance - MDR); superar toxicidade sistêmica ou para melhorar a relação ação versus eliminação, através do controle cinético e termodinâmico das reações envolvidas nos processos de substituição nucleofílica em complexos. ${ }^{5,6}$ Além disso, os híbridos precisam apresentar vantagens quando comparados ao ligante livre isoladamente, por isso a escolha do ligante deve ser feita levando em consideração alguns critérios, como baixa toxicidade e efeitos colaterais brandos. Baseado nisso, o uso de produtos naturais tem sido uma alternativa promissora na busca de novos complexos híbridos.

A piplartina, 5,6-di-hidro-1-[1-oxo-3-(3,4,5-trimetoxifenil)-2propenil]-2(1H)-piridinona (Figura 1), é uma amida de ocorrência natural isolada principalmente de espécies de plantas da família Piperaceae, sendo as espécies de Piper longum, P. tuberculatum, $P$. arborescens, $P$. chaba, P. Sylvaticum, $P$. cenocladum P. alatabaccum e $P$. puberulum consideradas fontes naturais de piplartina. ${ }^{7}$ Esta amida tem sido amplamente investigada devido as suas diversas e potentes atividades biológicas como as atividades antitumoral, ansiolítica, leishmanicida, antifúngica, antiagregante plaquetário, tripanocida e antinocepitiva, ${ }^{7,8}$ sendo um relevante modelo de molécula como protótipo para planejamento e desenvolvimento de novos fármacos.

*e-mail: clecio.ufrpe@gmail.com<smiles>COc1cc(/C=C/C(=O)N2CCC=CC2=O)cc(OC)c1OC</smiles>

Figura 1. Estrutura química da piplartina

A piplartina em testes in vivo apresentou efeito ansiolítico na dose de $50 \mathrm{mg} / \mathrm{kg}$ em camundongos, um potente efeito leishmanicida na dose de $30 \mathrm{mg} / \mathrm{kg}$ e atividade antitumoral em animais com sarcoma 180 nas doses de 50 e $100 \mathrm{mg} / \mathrm{kg} / \mathrm{dia}^{9-11}$ Em testes antifúngicos de bioautografia, a piplartina inibiu o crescimento do fungo fitopatogênico Cladosporium cladosporioides na concentração de $0,5 \mu \mathrm{g} /$ $\mu \mathrm{L} .{ }^{12} \mathrm{~A}$ piplartina exibiu atividade antibacteriana frente às bactérias patogênicas Klebsiella pneumonia, Pseudomonas aeruginosa e Staphylococcus aureus em testes usando o método de difusão em disco com raios de inibição 24, 20 e 16 mm, respectivamente. ${ }^{13}$

Derivados sintéticos da piplartina têm sido alvo de estudo para obtenção de compostos ativos com atividades antitumoral, antimicrobiana, inibidor da atividade da enzima aldose redutase e anti-inflamatória. ${ }^{14-16}$ Estudo prévio da relação estrutura-atividade da piplartina mostrou que derivados contendo o halogênio cloro no carbono $\alpha$-carbonílico do anel piperidínico aumentam a citoxicidade da piplartina, inibindo o crescimento tumoral in vivo para o câncer de pulmão em 48,5\% na dose de $2 \mathrm{mg} / \mathrm{kg} .{ }^{17}$ Estudos químicos e biológicos com a piplartina relatados previamente não têm sido direcionados para obtenção de complexos metálicos, sendo que muitos destes sistemas híbridos apresentam potentes atividades

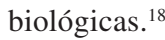

O uso farmacológico de complexos de vanádio (IV e V) tem sido amplamente relatado na literatura, ${ }^{19-21}$ isto devido aos efeitos insulino-miméticos e anti-diabéticos, in vitro ou in vivo, potenciais agentes antitumorais, anti-inflamatórios, antiparasitas, antivirais, antibacterianos e fungicidas. Considerando o potencial biológico da piplartina e dos complexos de vanádio (IV), o presente estudo foi direcionado para síntese e caracterização de um complexo de óxido-vanádio tendo como ligante a piplartina, e a avaliação de seu potencial antimicrobiano. 


\section{PARTE EXPERIMENTAL}

\section{Reagentes e solventes}

Os reagentes usados foram obtidos comercialmente com pureza P.A.: Acetato de etila (Dinâmica®), éter dietílico (Anidrol®), metanol (Isofar $\left.{ }^{\circledR}\right)$, etanol (Dinâmica $\left.{ }^{\circledR}\right)$, hexano (Fmaia®), clorofórmio deuterado (Sigma) e Sulfato de vanadila $\left(\mathrm{VOSO}_{4} \cdot 5 \mathrm{H}_{2} \mathrm{O}\right)(99 \%)$ Aldrich ${ }^{\circledR}$.

\section{Equipamentos}

As curvas de TG da piplartina e do respectivo complexo de vanadila (TGA) foram obtidas através de um equipamento TGA 50/50 da Shimadzu com cadinho de platina, usando como gás de arraste o nitrogênio $\left(50 \mathrm{~mL} \mathrm{~min}{ }^{-1}\right)$, com razão de aquecimento de $10^{\circ} \mathrm{C} / \mathrm{min}$ e uma faixa de temperatura de 30 a $800^{\circ} \mathrm{C}$. Os espectros de infravermelho foram obtidos em um espectrofotômetro modelo 640 - IR, com faixa do espectro de $400 \mathrm{a} 4000 \mathrm{~cm}^{-1}$, com as amostras preparadas em pastilhas de $\mathrm{KBr}$. O ponto de fusão foi obtido em um equipamento PFM-II-Tecnopono. O espectro de massas do complexo foi obtido em um espectrômetro Waters Xevo-G2-XS-QTof em módulo positivo com ionização por eletrosplay. O espectrofotômetro de infravermelho utilizado foi modelo 640 - IR da Varian. Os espectros de ressonância magnética nuclear (RMN) de ${ }^{1} \mathrm{H}$ e ${ }^{13} \mathrm{C}$ foram obtidos através de um aparelho Varian Mercury - 300 e $75 \mathrm{MHz}$, respectivamente, usando $\mathrm{CDCl}_{3}$ como solvente. Os espectros de absorção eletrônica foram obtidos fazendo uso de um espectrofotômetro UV-Vis, modelo 8453 da Agilent ${ }^{\circledR}$, com cubeta de quartzo de $1 \mathrm{~cm}$ e faixa espectral de 200 a $800 \mathrm{~nm}$, usando como solvente $\mathrm{CHCl}_{3}$.

\section{Extração da piplartina}

As raízes de Piper tuberculatum foram coletadas na reserva de Dois Irmãos na cidade de Recife - PE. O material vegetal foi autenticado pela Dra. Ângela Maria de Miranda Freitas, curadora do herbário Sérgio Tavares - UFRPE, do Departamento de Ciência Florestal, local onde a exsicata foi preparada e depositada sob o número: HST 18179. As raízes foram secas em estufa a $50^{\circ} \mathrm{C}$ por $48 \mathrm{~h}$ e posteriormente trituradas em moinho de facas, resultando em $165 \mathrm{~g}$ do material, que foi submetido à extração por maceração a frio por três vezes com uma mistura de $300 \mathrm{~mL}$ de éter dietílico: acetato de etila (2:1). Após a filtração o solvente foi removido em evaporador rotatório a $40^{\circ} \mathrm{C}$ sob pressão reduzida para fornecer $2,8 \mathrm{~g}$ de extrato bruto seco com presença de sólidos cristalinos. O extrato foi lavado com metanol por 3 vezes para obter $0,8 \mathrm{~g}$ de um sólido branco que foi caracterizado por $\mathrm{RMN} \mathrm{de}{ }^{1} \mathrm{H} \mathrm{e}{ }^{13} \mathrm{C}$.

\section{Síntese do complexo}

O complexo de vanádio (IV) com a piplartina foi obtido a partir da mistura de uma solução de piplartina $(0,50 \mathrm{mmol}, 48,6 \mathrm{~g}) \mathrm{em}$ $10 \mathrm{~mL}$ de etanol com a solução de sulfato de vanadila hidratado $(0,25 \mathrm{mmol}, 12,12 \mathrm{~g})$ em $20 \mathrm{~mL}$ de água destilada em agitação por $24 \mathrm{~h}$ (Esquema 1). A mistura reacional foi rotaevaporada e posteriormente liofilizada, obtendo um sólido esverdeado.

\section{Atividade biológica}

\section{Culturas de microrganismos}

O potencial antimicrobiano da piplartina e do composto de coordenação foi avaliado frente às bactérias gram-positivas Staphylococcus aureus (UFPEDA 02), Bacillus subtilis (UFPEDA 86), Enterococcus faecalis (UFPEDA 138) e as bactérias gramnegativas: Escherichia coli (UFPEDA 224), Klebsiella pneumoniae (UFPEDA 396), Pseudomonas aeruginosa (UFPEDA 416), bem como para o fungo filamentoso Microsporum gypseum (UFPEDA 2565). As bactérias e fungo foram provenientes da coleção de microrganismos do Departamento de Antibióticos da Universidade Federal de Pernambuco. A suspensão dos microrganismos foi padronizada pela turvação equivalente ao tubo 0,5 da escala de McFarland em água destilada, correspondente a uma concentração de aproximadamente $10^{8} \mathrm{UFC} / \mathrm{mL}$ para bactérias e $10^{7} \mathrm{UFC} / \mathrm{mL}$ para fungos. ${ }^{21}$

\section{Determinação da Concentração Mínima Inibitória (CMI)}

A CMI foi realizada através da técnica de microdiluição em multiplacas com 96 poços..$^{21}$ Os meios de cultura empregados foram o Ágar Sabourand (para fungo) e Ágar Muelle-Hinton (para bactérias). O Metronidazol $(2,5 \mu \mathrm{g} / \mathrm{mL})$ e Fluconazol $(2,5 \mu \mathrm{g} / \mathrm{mL})$ foram usados como controle positivo, enquanto o álcool etílico como controle negativo. As análises foram realizadas em triplicata e as microplacas foram cultivadas à $37^{\circ} \mathrm{C}$ por $18-24 \mathrm{~h}$ para bactérias e $30^{\circ} \mathrm{C}$ por $48-72 \mathrm{~h}$ para o fungo. Após o período de cultivo, as microplacas foram reveladas com a adição de $10 \mu \mathrm{L}$ da solução de risazurina a $0,01 \%$ e incubadas por $3 \mathrm{~h} \cdot{ }^{23} \mathrm{~A}$ CMI foi definida como a menor concentração da amostra que inibiu o crescimento do microrganismo, com concentração final de $2500 \mu \mathrm{g} \mathrm{mL} \mathrm{m}^{-1}$.

\section{RESULTADOS E DISCUSSÃO}

Um sólido cristalino com ponto de fusão de $122,2^{\circ} \mathrm{C}$ foi isolado das raízes de $P$. tuberculatum com rendimento de 30,8\% em relação à massa extrato bruto e 1,7\% em relação à massa das raízes secas, sendo caracterizado como a piplartina, após interpretação e comparação de seus dados espectrais de IV, RMN ${ }^{1} \mathrm{H}$ e ${ }^{13} \mathrm{C}$ com os dados relatados previamente. ${ }^{24}$

O complexo híbrido produzido se apresentou na forma de um sólido de coloração verde com rendimento reacional de $75 \%$, e solubilidade em água e metanol. Os espectros de absorção eletrônica da piplartina e do complexo V-PIP são mostrados na Figura 2.<smiles></smiles><smiles>COc1cc(/C=C/C(=O)N2CCC=CC2=O)cc(OC)c1OC</smiles> 


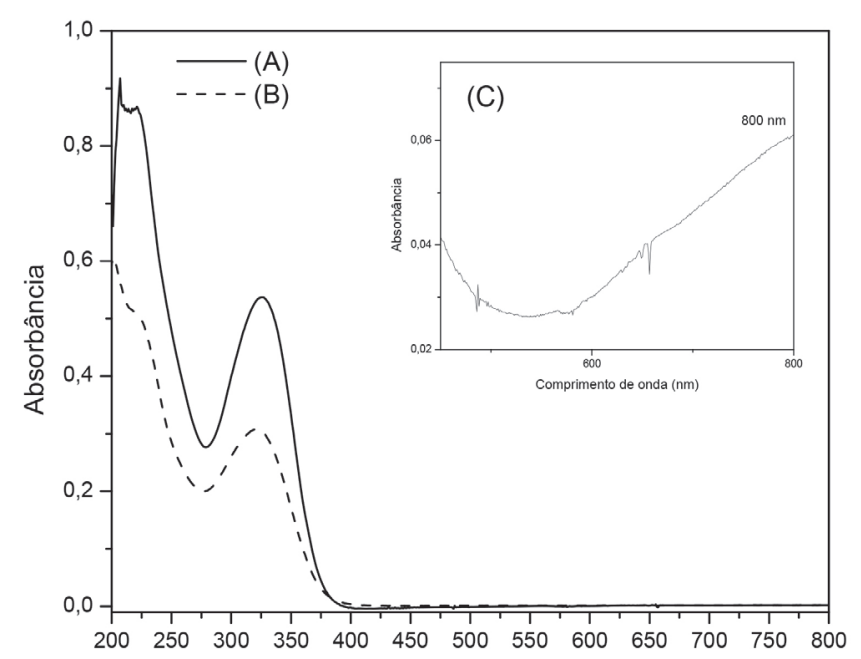

Figura 2. Espectros de absorção eletrônica do ligante piplartina (A), e do complexo V-PIP (B e C), com janela de 200-800 nm e ampliação da região entre 400-800 $\mathrm{nm}$, respectivamente

O espectro de absorção da piplartina apresentou uma absorção máxima em 210, 220 e $325 \mathrm{~nm}$, associados a transições $\pi \rightarrow \pi^{*}$, sendo a banda em $325 \mathrm{~nm}$ associada aos cromóforos dos dois grupos $\alpha, \beta$-insaturados. Analisando o espectro de absorção eletrônica do V-PIP é possível observar deslocamento hipsocrômico nas duas primeiras bandas, que no complexo estão em 200 e $210 \mathrm{~nm}$ (erro associada à medida $\leq 4 \mathrm{~nm}$ ). Essa similaridade entre os espectros de absorção deve-se ao íon vanadila estar coordenado a sítios que apresentam bandas de baixa intensidade (transições proibidas). No espectro de absorção do complexo V-PIP, na região do visível Figura 2 (C) observa-se uma banda de absorção em 800 nm (região do vermelho, complexo com coloração verde) referente à transição d-d do íon vanadila, que segundo sua configuração eletrônica $\left(\mathrm{d}^{1}\right)$ apresenta apenas uma banda de absorção, corroborando com o esperado segundo o Diagrama de Orgel. Na Figura 3 são apresentados os espectros de infravermelho da piplartina e do complexo V-PIP.

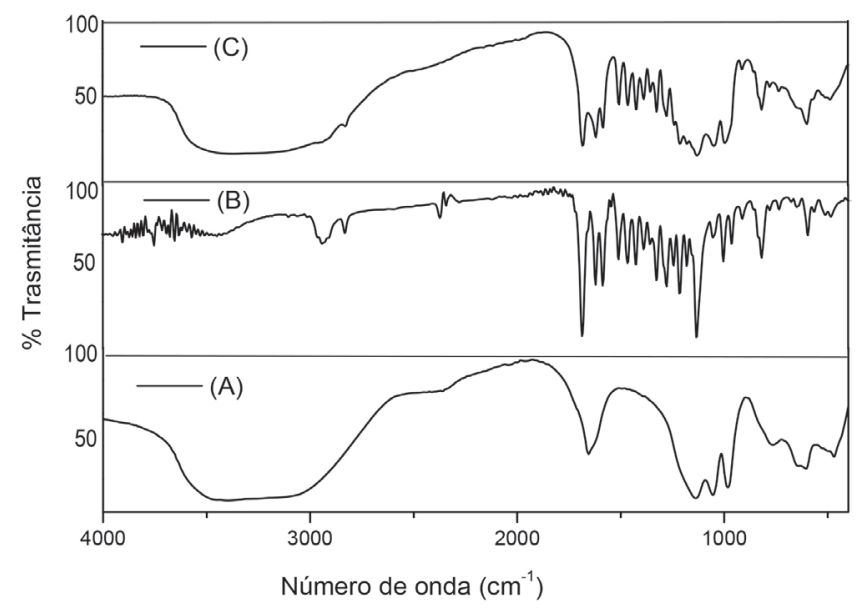

Figura 3. Espectros de Infravermelho do $\mathrm{VOSO}_{4}(A)$, piplartina (B) e V-PIP (C)

$\mathrm{O}$ espectro de infravermelho do $\mathrm{VOSO}_{4}$, Figura 3(A), apresentou a banda característica da ligação $\mathrm{V}=\mathrm{O}$ (íon vanadila $-\mathrm{VO}^{2+}$ ) em $990 \mathrm{~cm}^{-1}$, e duas bandas na região de 3432 e $3322 \mathrm{~cm}^{-1}$ referentes a moléculas de água livres e coordenadas, respectivamente. Ao comparar o espectro de infravermelho da piplartina com o complexo V-PIP, observa-se a presença de uma banda em $910 \mathrm{~cm}^{-1}$, no complexo, referente ao estiramento $\mathrm{V}=\mathrm{O}$ presente no complexo. ${ }^{25}$ Esta banda encontra-se deslocada quando comparado ao espectro de infravermelho do sulfato de vanadila, devido à coordenação do íon vanadila às carbonilas presentes na estrutura da piplartina. Outra evidência desta coordenação é o deslocamento da banda de estiramento $\mathrm{C}=\mathrm{O}$ na piplartina $\left(1700 \mathrm{~cm}^{-1}\right)$ e no complexo V-PIP $\left(1684 \mathrm{~cm}^{-1}\right)$. Este deslocamento de banda não se assemelha aos casos de coordenação de metais às $\beta$-dicetonas em que o próton alfa foi removido, propiciando a ressonância entre as carbonilas existentes. Apesar disso, a coordenação do íon vanadila às carbonilas da piplartina é sugerida, uma vez que, segundo a equação para determinação do número de onda, em um oscilador harmônico, a constante de força da ligação $\mathrm{C}=\mathrm{O}$ diminui e a massa reduzida aparente aumenta. Em ambos os espectros do complexo e do ligante apresentaram bandas intensas de deformação axial de $\mathrm{C}-\mathrm{O}-\mathrm{C}$ em $1129 \mathrm{~cm}^{-1}$, referentes às metoxilas aromáticas. No complexo V-PIP também são observadas duas bandas em 3432 e $3322 \mathrm{~cm}^{-1}$ referentes a moléculas de água livres (águas de hidratação) e coordenadas, respectivamente. Na Figura 4 são apresentadas as curvas de TG da piplartina e V-PIP, sobrepostos.

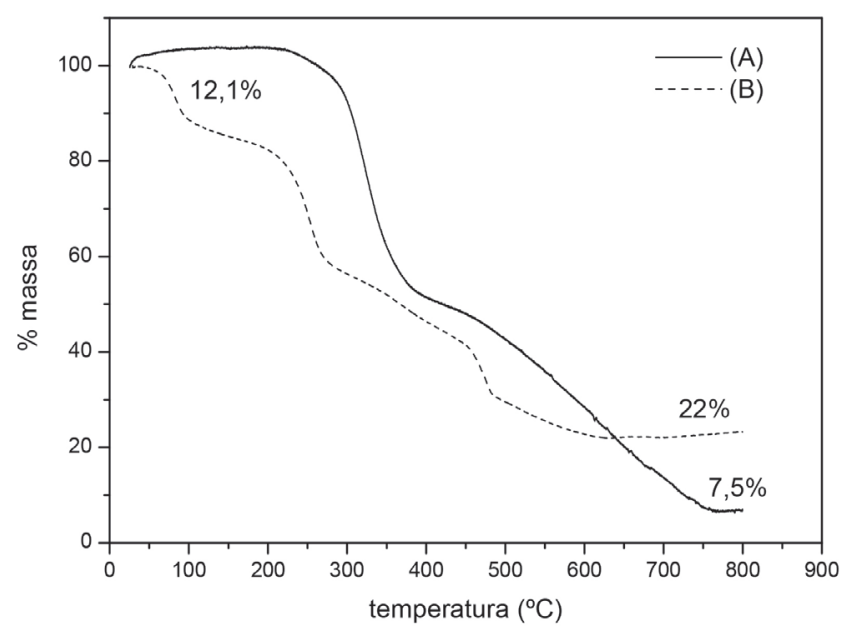

Figura 4. Curvas de TG do ligante piplartina e do complexo V-PIP, sobrepostos

A curva de TG da piplartina, Figura 4(A), apresentou três eventos térmicos simultâneos, sendo o final em $760{ }^{\circ} \mathrm{C}$ e correspondente a um resíduo de 7,5\% em massa. Este percentual corresponde a um resíduo de $2 \mathrm{C}$, pois a medida foi realizada em atmosfera redutora. A temperatura onset observada foi de $263{ }^{\circ} \mathrm{C}$.

No caso da curva de TG do complexo V-PIP, Figura 4(B), foram observados quatro eventos térmicos, e a temperatura onset foi em $210^{\circ} \mathrm{C}$ (retirando o evento associado a moléculas de água). O primeiro evento em $100{ }^{\circ} \mathrm{C}$ corresponde a $12,1 \%$ em massa, o que corresponde a quatro moléculas de água de hidratação na estrutura do complexo. A perda de massa final, em $620^{\circ} \mathrm{C}$, deixa um resíduo correspondente a $22 \%$ em massa, o que se atribui ao $\mathrm{VO}_{2}$ e $4 \mathrm{C}$ (atmosfera redutora). No Esquema 2 são apresentadas as etapas de perda de massa no complexo V-PIP.

O espectro de massas do complexo V-PIP é apresentado na Figura 5.

Através do espectro de massas do complexo V-PIP, Figura 5, é possível observar o pico referente ao fragmento da massa molecular do composto $\mathrm{m} / \mathrm{z}[\mathrm{M}+\mathrm{K}]^{+}=459,3263$ Da referente ao pseudo íon molecular do complexo formado. O pico base em $\mathrm{m} / \mathrm{z}=318,3014$ Da foi atribuído a massa molar do ligante piplartina que corresponde ao fragmento do complexo $\left[\mathrm{M}-\mathrm{VO}-2 \mathrm{H}_{2} \mathrm{O}+1\right]^{+}$e sendo observado também o fragmento do cátion acílio referente ao pico $\mathrm{m} / z=221,0847$ Da, fragmentação principal da piplartina.

Com base nos dados de análise térmica, espectroscopia de 


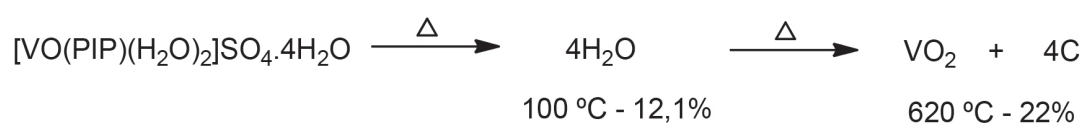

Esquema 2. Decomposição do complexo V-PIP por TGA

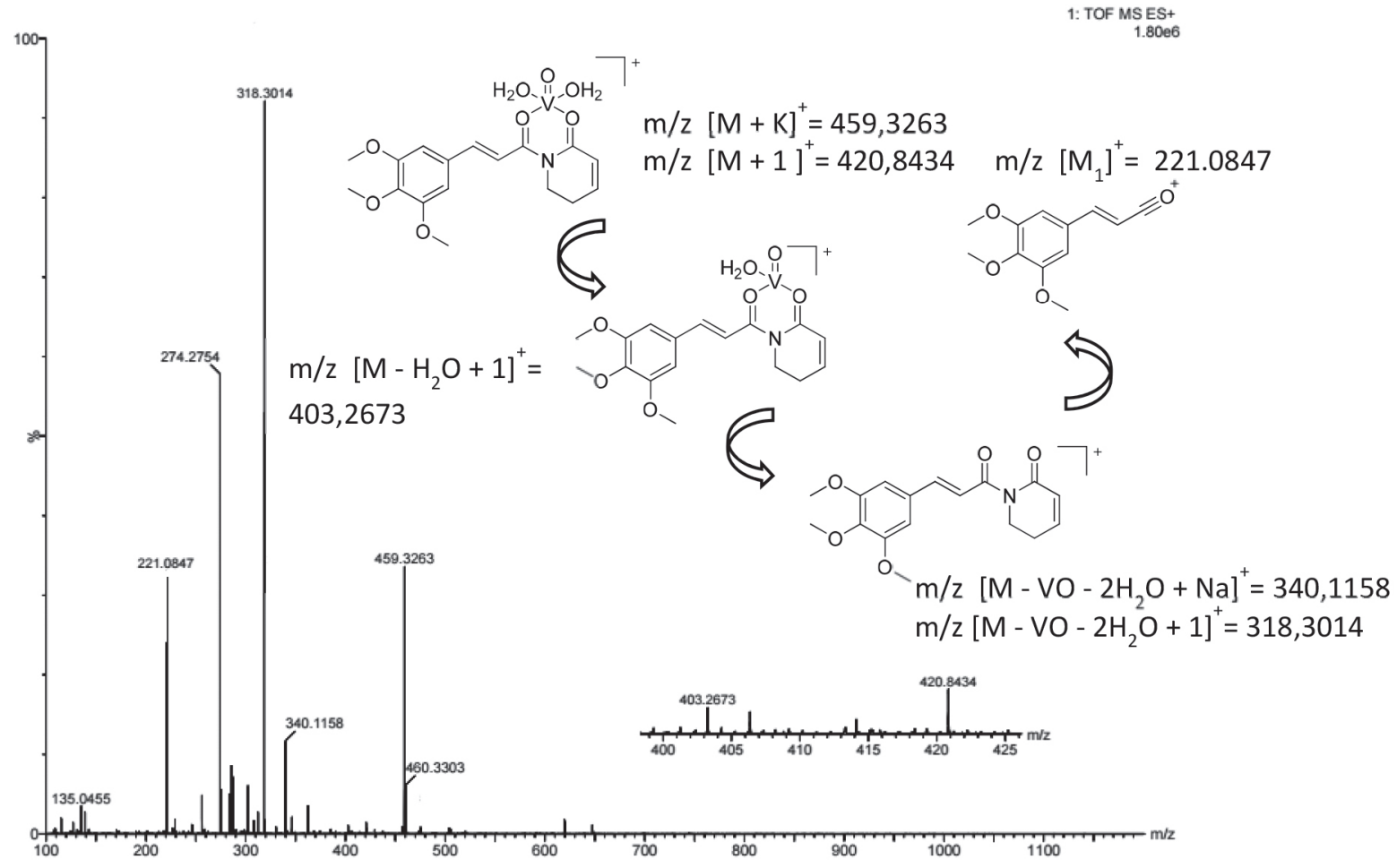

Figura 5. Espectro de massas do complexo V-PIP, analisado em modo positivo, com destaque no pseudo íon molecular $\left[\operatorname{VO}(\mathrm{PIP})\left(\mathrm{H}_{2} \mathrm{O}\right)_{2}+\mathrm{K}\right]^{+}$

infravermelho e espectrometria de massas foi possível propor uma fórmula mínima que corrobore com todos os resultados obtidos, sendo esta [VO(PIP) $\left.\left(\mathrm{H}_{2} \mathrm{O}\right)_{2}\right] \mathrm{SO}_{4} \cdot 4 \mathrm{H}_{2} \mathrm{O}$. Com base nesta fórmula mínima foi calculado o erro relativo entre a massa calculada (fórmula mínima proposta) e o valor experimental (obtido a partir do espectro de massas), apresentando um valor de $0,03 \%$.

Baseado na interpretação dos dados de espectroscopia de absorção eletrônica, espectroscopia de infravermelho, curvas de TG e espectrometria de massas, o sólido esverdeado obtido da reação da piplartina com o sulfato de vanadila foi caracterizado como sendo o complexo V-PIP.

\section{Atividade antimicrobiana}

Os valores das CMI estão apresentados na Tabela 1 e o complexo V-PIP apresentou menores concentrações capazes de inibir o crescimento das bactérias e fungo quando comparado à piplartina, principalmente para as bactérias gram negativas. A piplartina apresentou CMI que variou de 312,5 a $1250 \mu \mathrm{g} \mathrm{mL}^{-1}$, sendo que valores de concentrações $\leq 500 \mu \mathrm{g} \mathrm{mL}^{-1}$ para material vegetal são considerados ativos e valores de 600 a $1500 \mu \mathrm{g} \mathrm{mL}{ }^{-1}$ são considerados moderados. ${ }^{6,27}$ O complexo V-PIP apresentou valores da CMI que variaram de 156,2 a $625 \mu \mathrm{g} \mathrm{mL}{ }^{-1}$, sendo o menor valor observado para a bactéria $E$. coli com CMI de 156,2 $\mu \mathrm{g} \mathrm{mL}^{-1}$. O complexo frente o fungo $M$. gypseum apresentou uma menor CMI $\left(312,5 \mu \mathrm{g} \mathrm{mL}^{-1}\right)$ quando comparado com a CMI $(625 \mu \mathrm{g} / \mathrm{mL})$ do ligante piplartina. O sulfato de vanadila usado na síntese do complexo V-PIP também apresentou atividade antimicrobiana, principalmente frente à bactéria gram negativa $K$. Pneumonial com CMI de $156,2 \mu \mathrm{g} \mathrm{mL}^{-1}$ e o fungo M. gypseum com CMI de 312,2 $\mu \mathrm{g} / \mathrm{mL}$, revelando-se um antimicrobiano em potencial.
Tabela 1. Concentração Mínima Inibitória - CMI da piplartina, complexo V-PIP e sulfato de vanadila em $\mu \mathrm{g} / \mathrm{mL}$

\begin{tabular}{|c|c|c|c|c|}
\hline \multicolumn{5}{|c|}{ Concentração Mínima Inibitória - CMI ( $\mu \mathrm{g} / \mathrm{mL})$} \\
\hline \multicolumn{2}{|c|}{ Microrganismos } & Piplartina & V-PIP & $\mathrm{VOSO}_{4}$ \\
\hline \multirow{3}{*}{$\begin{array}{l}\text { Bactérias } \\
\text { Gram Positivas }\end{array}$} & E. faecalis & 625 & 312,5 & 625 \\
\hline & S. aureus & 625 & 625 & 1250 \\
\hline & B. subtilis & 1250 & 312,5 & 625 \\
\hline \multirow{3}{*}{$\begin{array}{l}\text { Bactérias } \\
\text { Gram Negativas }\end{array}$} & E. coli & 312,5 & 156,2 & 625 \\
\hline & K. pneumonial & 1250 & 625 & 156,2 \\
\hline & P. aeruginosa & 1250 & 625 & 1250 \\
\hline Fungo & M. gypseum & 625 & 312,5 & 156,2 \\
\hline
\end{tabular}

\section{CONCLUSÃO}

O complexo de piplartina com o íon vanadila foi sintetizado e caracterizado por diversas técnicas, resultando em um composto de coordenação de fórmula $\left[\mathrm{VO}(\mathrm{PIP})\left(\mathrm{H}_{2} \mathrm{O}\right)_{2}\right] \mathrm{SO}_{4} \cdot 4 \mathrm{H}_{2} \mathrm{O}$. Esse complexo, quando comparado a piplartina, apresentou solubilidade em meio aquoso, sendo essa uma propriedade física relevante para compostos candidatos a fármacos. O complexo V-PIP apresentou menores concentrações capazes de inibir o crescimento das bactérias e fungo quando comparado com piplartina, principalmente para as bactérias gram negativas, sugerindo que a presença do íon vanadila exerceu um efeito sinérgico sobre a atividade biológica da piplartina. Adicionalmente, o presente estudo revelou o sulfato de vanadila como um promissor composto antimicrobiano. As relevantes mudanças 
físicas e biológicas da piplartina, quando complexada com sulfato de vanadila e associadas ao potencial biológico da amida e do sal, tornam o novo complexo V-PIP descrito aqui um interessante composto para as investigações de novas atividades biológicas.

\section{MATERIAL SUPLEMENTAR}

Os espectros de $\mathrm{RMN}{ }^{1} \mathrm{H}$ e ${ }^{13} \mathrm{C}$ bem como as atribuições dos valores dos deslocamentos químicos para a amida piplartina estão disponíveis no http://quimicanova.sbq.org.br (Tabela 1S, Figuras 1S e $2 \mathrm{~S}$ ), em arquivo pdf, com livre acesso.

\section{AGRADECIMENTOS}

Ao Centro de Apoio à Pesquisa da UFRPE (CENAPESQ). Ao CNPq pelo apoio financeiro do projeto Universal 14/2013 (Processo: 472382/2013-6). À CAPES pela bolsa de mestrado concedida.

\section{REFERÊNCIAS}

1. N'soukpoé-Kossi, C. N.; Descôteaux, C.; Asselin, E.; Tajmir-Riahi, H.A.; Bérubé, G.; DNA Cell Biol. 2008, 27, 101.

2. Schobert, R.; Bernhardt, G.; Biersack, B.; Bollwein, S.; Fallahi, M.; Grotemeier, A.; Hammond, G. L.; Chem. Med. Chem. 2007, 2, 333.

3. Huxley, M.; Sanchez-Cano, C.; Browning, M. J.; Navarro-Ranninger, C.; Quiroga, A. G.; Rodger, A.; Hannon, M.; J.; Dalton Trans. 2010, 39, 11353.

4. Schobert, R.; Biersack, B.; Dietrich, A.; Knauer, S.; Zoldakova, M.; Fruehauf, A.; Mueller, T.; J. Med. Chem. 2009, 52, 241.

5. Wang, X.; Guo, Z.; Dalton Trans. 2008, 1521.

6. Wang, L.; Gou, S.; Chen, Y.; Liu, Y.; Bioorg. Med. Chem. Lett. 2005, 15, 3417

7. Bezerra, D. P.; Pessoa, C.; Moraes, M. O.; Saker-Neto, N.; Silveira, E. R.; Lotufo, L. V. C.; Eur. J. Pharm. Sci. 2013, 48, 453.

8. Bezerra, D. P.; Pessoa, C.; Moraes, M. O.; Costa-Lotufo, L. V.; Rubio Gouvea, D.; Jabor, V. A. P.; Lopes, N. P.; Borges, K. B.; Lima, M. A. S.; Silveira, E. R.; Quim. Nova 2012, 3, 460

9. Bezerra, D. P.; Militao, G. C. G.; Oliveira De Castro, F.; Pessoa, C.; Odorico De Moraes, M.; Silveira, E. R.; Lima, M. A. S.; Elmiro, F. J. M.; Costa-Lotufo, L. V.; Toxicol. In Vitro 2007, 21, 1.
10. Bodiwala, H. S.; Singh, G.; Singh, R.; Dey, C. S.; Sharma, S. S.; Bhutani, K. K.; Singh, I. P.; J. Nat. Med. 2007, 61, 418.

11. Bezerra, D. P.; Castro, F. O.; Alves, A. P. N. N.; Pessoa, C.; Moraes, M. O.; Silveira, E. R.; Lima, M. A. S.; Elmiro, F. J. M.; Costa-Lotufo, L. V.; Braz. J. Med. Biol. Res. 2006, 39, 801.

12. Silva, R. V.; Navickiene, H. M. D.; Kato, M. J.; Bolzani, V. S.; Méda, C. I.; Young, M. C. M.; Furlan, M.; Phytochemistry 2002, 59, 521.

13. Prasanna, K. P.; Ganapathy, P. S. S.; Naika, L. R.; Pharmacophore 2010, $2,141$.

14. Kumar, J. U.; Shankaraiah, G.; Kumar, R. S. C.; Pitke, V. V.; Rao, G. T.; Poornim, B.; Babu, K. S.; Sreedhar, A. S.; J. Asian Nat. Prod. Res. 2013, 15,658 .

15. Rao, V. R.; Muthenna, P.; Shankaraiah, G.; Akileshwari, C.; Babu, K. H.; Suresh, G.; Suresh Babu, K.; Kumar, R. S. C.; Prasad, K. R.; Potharaju Ashok Yadav, P. A.; Petrash J. M.; Reddy, G. B. K.; Madhusudana Rao, J.; Eur. J. Med. Chem. 2012, 57, 344

16. Seo, Y. H.; Kim, J-K.; Ju, J-G.; Bioorg. Med. Chem. Lett. 2014, 24, 5727.

17. Wu, Y.; Min, X.; Zhuang, C.; Li.; J.; Yu, Z.; Dong, G.; Yao, J.; Wang, S.; Liu, Y.; Wu, S.; Zhu, S.; Sheng, C.; Wei, Y.; Zhang, H.; Zhang, W.; Miao, Z.; Eur. J. Med. Chem. 2014, 82, 545.

18. Olar, R.; Dogaru, A.; Marinescu, D.; Badea, M.; J. Therm. Anal. Calorim. 2012, 110, 257.

19. Thompson, K. H.; Lichter, J.; Lebel, C.; Scaife, M. C.; McNeill, J. H. Orvig, C.; J. Inorg. Biochem. 2009, 554, 558.

20. Thompson, K. H.; Orvig, C.; Coord. Chem. Rev. 2011, 219, 1053.

21. Pessoa, J. C.; Etcheverry, S.; Gambino, D.; Coord. Chem. Rev. 2014, $301,24$.

22. Clinical and Laboratory Standards Institute; Reference Method for Broth Dilution Antifungal Susceptibility Testing of Yeasts and Filamentous Fungi. Approved standard: M27-A3 e M38-A2. Wayne (PA): CLSI, 2008.

23. Clinical and Laboratory Standards Institute; Performance Standadrds for Antimicrobial Susceptibility Testing. Twentieth Informational Supplement: M100-S20 e M100-S20-U. Wayne (PA): CLSI, 2010.

24. Duh C-Y.; Wu, Y-C.; Wang, S-K.; Phytochemistry 1990, 29, 2689.

25. Mosmann, T.; J. Immunol. Methods. 1983, 63, 65.

26. Barbosa, A. C.; Dissertação de Mestrado, Universidade de São Carlos, Brasil, 2005.

27. Wong-Leung, Y. L.; Fitoterapia 1988, 69, 11. 